\title{
Research on Adult English Teaching Under the Condition of Multimedia Network*
}

\author{
Linlin Yang \\ School of Public Administration \\ Liaoning Radio and TV University \\ Liaoning Equipment Manufacturing Vocational and Technical College \\ Shenyang, China 110161
}

\begin{abstract}
The progress of multimedia network technology has promoted the reform and development of adult education in China. At present, the use of multimedia network information technology through distance learning can meet the diversified social development requirements and adult student learning needs. It breaks the limits of time and space, so that people can learn anytime and anywhere, which has changed the learning method of adults. Colleges and universities should increase the construction of multimedia network resources, make full use of important teaching resources, speed up the exploration of adult English learning methods and build a complete adult English teaching system, so as to promote China's adult English teaching standards and achievements to advance to higher goals.
\end{abstract}

Keywords-English teaching; adult vocational college; multimedia network technology

\section{INTRODUCTION}

In adult education, the traditional approach to English teaching is somewhat rigid, so it is difficult to stimulate adult students' enthusiasm for learning, resulting in poor quality of adult English teaching. The employing units have questioned adult English teaching, which is not conducive to the survival and development of adult English teaching. It is also difficult to train adult students into talents that meet the needs of society and businesses.

With the advancement of science and technology, effective integration of English teaching with multimedia and network technology has become the main form of implementation of adult English teaching and lifelong education. This paper analyzes the advantages of multimedia network technology in adult English teaching, and discusses the strategies of using multimedia networks for adult English teaching based on the cognitive characteristics of adult learners to create the classroom environment that matches the work environment and teaching content and the autonomous learning environment on the internet after class, and construct the teaching mode of classroom teaching and online tutorials after class to improve the effectiveness of

*[Fund Project] 2017 Adult Education Research Center of Liaoning Province Adult Education Research Project "Research on Adult Higher Vocational English Teaching Strategies under Multimedia Network Conditions", project number: LC1720. teaching.

\section{ThE CURRENT SituATION OF AdULT ENGLISH TEACHING}

\section{A. The General English Level of Adult Vocational Students Is not High}

Adult students are not capable of speaking, listening and writing, so they are frustrated in learning. Although students have already learned basic knowledge of grammar in elementary and junior high schools, they have accumulated a small amount of vocabulary and the vocabulary is only remain at the status of rote memorization. And their English level was also uneven. This has brought many difficulties to English teaching, which is also the main difficulty in adult higher vocational English teaching.

\section{B. Constraint of Traditional Teaching Model}

Adult English teaching usually adopts the large class system with a large capacity of class, which make it not easy for teachers to manage and difficult to teach students in accordance with their aptitude. The English class teaching process mostly adopts teacher-centered model where teachers speaking and students passively absorb but do not know how to use. Teachers seldom take into account the students' feelings and opinions. The lack of two-way communication eventually causes "dumb English". The model used in the adult English teaching is the traditional teaching method of "cramming education" by using chalk and blackboard. In order to complete the teaching plan, some teachers just teach according to the textbooks without updating the teaching content. Some teachers only give the students the scope and focus of the examination to complete the teaching task in order to let the students cope with the examination. Some adult teachers lack professionalism and pay less attention on adult education, so they rarely switch effective teaching methods or teaching methods to adapt to the characteristics of adult students in English learning, which greatly reduces the enthusiasm of adult students in learning English. 


\section{Single Teaching Method}

The traditional teaching methods of using chalk and blackboard and the single, systematic and detailed teaching method are relatively rigid, which cannot take into account the needs of students and cannot motivate students to learn English. Most adult students have been out of school for many years, with certain amount of knowledge background and life experience and their own unique knowledge. Teachers' single teaching and rote learning language training limit the knowledge and spatial thinking ability of adult students and reduce the transmission quantity of information, which may also be annoying to students, resulting in no response in the classroom and poor teaching effectiveness. By making use of relevant functions of network technology, teachers break through the limits of time and space in classroom teaching, and can share learning resources and exchanges between teachers and students, to realize the flexibility of adult English teaching.

\section{Limited Teaching Hours}

Adult learners have weak listening and speaking skills, poor pronunciation and intonation, and a small vocabulary. However, the training of English listening, speaking, reading and writing takes time, the teaching hours for adult students seems very limited. In addition, currently adult English is still test-oriented. Therefore, teachers need to complete the teaching of word reading, text interpretation, translation, and practice explanation within a limited number of hours, which results in insufficient training in listening, speaking, reading and writing, so that basic skills can't get comprehensive training, and the improvement of overall ability is affected. Thus, students with poor foundation feel even more difficult to learn.

\section{E. Old Textbook}

At present, many textbooks used for adult English teaching are obsolete. Some textbooks have been used for more than 20 years and the contents are obsolete, which are severely disconnected from today's social life and work environment. Some schools directly use textbooks of fulltime colleges and universities for adults to teach. The large capacity and difficulty bring great ideological pressure and frustration to adult learners.

\section{ThE DEVELOPMENT OF AdULt ENGLISH TEACHING}

In the context of vigorous promotion of lifelong education, English has become an indispensable course. Adult English teaching has gone from the initial traditional education to the present open education. At present, to get a good development, it is necessary for adult English teaching to upgrade the teaching philosophy, strictly manage the teaching, select or prepare practical teaching materials that are suitable for adult students centering on students, formulate distinctive courses, and update course teaching models to enrich teaching evaluation methods so that we can fundamentally overcome the weaknesses of adult English teaching.
With the rapid development of computer network multimedia technology, multimedia technology-assisted teaching is gradually used in adult English teaching practice. It combines text, pictures, video, animation, audio, etc. to complete a series of human-computer interaction operation teaching systems. It has presented realistic effects for teaching, expanded adult perception space, and innovated adult English education. We can use multimedia to effectively organize teaching content, guide students to master what they have learned, and enhance understanding of theoretical knowledge through extensive man-machine dialogue exercises to strive to achieve good teaching results and promote the steady development of adult English teaching.

\section{AdUlT ENGLISH TEACHING UNDER THE CONDITION OF MUlTimedia NETWORK}

For the current situation of adult vocational English teaching, we should improve the traditional teaching methods, use modern multimedia network technology, enrich the teaching content, create a flexible and interactive classroom atmosphere, and promote student self-learning. This needs to give full play to the advantages of multimedia networks, and actively explore adult education strategies for higher vocational English under the perspective of multimedia networks, so that adult English teaching in higher vocational colleges can really exert its effectiveness.

\section{A. Using Multimedia Network Teaching to Stimulate Interest in English Learning}

We can use modern network technology, integrate multimedia teaching resources, including text, pictures, sound, video, and animation, etc., to perform a comprehensive performance and provide a very realistic simulation environment, so that students feel strong sense of participation and the classroom teaching will be more vivid and intuitive, visual, easy to understand and grasp, and easy to achieve the purpose of dissemination of knowledge. This will enhance students' learning enthusiasm and sense of accomplishment. At the same time, using the interactive learning APP provided by the Internet and new media platforms to supplement, extend and develop the teaching content in a timely manner will improve the teaching efficiency.

\section{B. Realizing Teacher-student Real-time Interaction Using Network Interactive Platform}

The development of network and multimedia technology has promoted the development of the English learning system. It has also provided a convenient channel for exchanges between teachers and students. At the same time, students' enthusiasm and initiative have been fully stimulated. Through the Internet and new media platforms, such as QQ, WeChat, and Rain Classroom, real-time communication between teachers and students can be realized to understand student learning situation, review assignments and give guidance and results; students can upload homework, selftest questions for teachers to review, correct and give 
feedback, and comb the knowledge based on the teacher's recommendation.

\section{Using Multimedia Networks to Create Flexible Teaching Methods and Enrich Teaching Content}

Using the Internet can enable distance education and gather adult students from all over the world to learn together on the same platform. As long as they have an internet connection and $\log$ in on the web platform, adult students can participate in a variety of learning projects and content according to their needs and time whenever and wherever. They can also choose the courses for titles examination, professional English classes, oral training, or strengthening the use of a certain English using skill.

Adult English education based on multimedia network information technology can provide more diverse and richer teaching and learning materials. With the development of multimedia technology, teachers can produce and provide students with vivid and practical multimedia learning materials such as texts, pictures, sounds and micro lessons. Students can obtain the learning and practice materials they need at any time, so that the long-term learning enthusiasm of adult students can be promoted and the fun and efficiency of learning is improved.

\section{Using Multimedia Network Teaching to Achieve Individualized Teaching}

Network and multimedia teaching can adapt to the learning needs of students at different levels and implement teaching according to their aptitude. The network provides an extremely rich listening and speaking resource for English teaching. The content is full, interesting, vivid and practical. According to the actual situation of students and different levels of learning requirements, teachers can choose or make corresponding teaching contents in English level and provide learning aids in different schedules and ways to supplement the knowledge of British and American culture and British and American literature for outstanding students to expand students' horizons and help them make progress towards higher levels; require students with poor basics to complete text understanding and after-school exercises and supplement content of English test. Students can train themselves according to their study habits, English basics, listening and speaking skills, and study time, arrange learning progress, and complete learning tasks. Using the network multimedia platform, teachers effectively teach students in accordance with their aptitude, which can fully exert the initiative, enthusiasm and creativity of students in the teaching process. Using multimedia means, we create a teaching environment that integrates sound, light, color, and figure, and a relaxed and autonomous learning atmosphere to promote students' learning of subjective initiative and personality development.

\section{E. Creating a Situation to Allow Students to Feel the English Atmosphere}

Language as a tool for communication requires language environment and language practice. The use of Internet and multimedia technology can create intuitive, real-world situations for students and provide students with an immersive feel. Teachers can edit teaching materials, play audio and video materials, create situational scenarios and other channels to provide students with language contexts based on learning content; add English and American culture and English learning atmosphere by appreciation of classic English songs or English movie clips; students play the plots in the material in the text or multimedia; students with higher English proficiency are encouraged to practice English communication skills through the Internet and foreign teachers. In this way, students are provided with a large amount of linguistic information stimuli. In English teaching, the advantages of the Internet and multimedia are fully utilized, English learning situations are created, and students' enthusiasm for English learning and teaching effects are enhanced.

\section{F. Strengthening Teachers Guiding Ability}

In the adult English teaching mode under multimedia network conditions, teachers should no longer play the roles of professors and inculcator in traditional classroom teaching, but should be the role of organizers, mentors, and explainer. They should guide students to search information through the Internet or library, guide students to conduct independent learning targeted with clear focus, timely check the students' learning status, answer students' difficult questions, summarize the text points and explain the language focus, to further sublimate students' knowledge. Adult English teaching needs to emphasize the training of language skills on the basis of completing the basic teaching content, do a good job of guiding students in learning and planning, and allow students to develop their own practical skills in the process of independent learning.

\section{G. Optimizing Assessment Methods}

With the reform of adult English teaching methods and teaching content, the examination system and evaluation methods must also be reformed accordingly. The model of combination of formative assessment and final assessment is implemented, and the examination will be gradually transformed into the assessment of practice and comprehensive quality of English language skills. Formative assessment includes self-assessment of trainees, assessment among trainees, assessment of trainees by teachers and assessment of trainees by education department, etc. It mainly evaluates and supervises students' learning process by recording the performance of students' attendance, classroom performance, and participation in activities, presentation in the classroom, online learning, classroom test, and usual homework, etc. and on this basis, formative assessment results will be calculated. The final assessment refers to the final course examination and the proficiency level test. After the adult students participate in the final written and oral examinations, the final assessment results of the course are weighted by the written test score, oral test score, and formative test score. Regarding the content of the assessment, it is necessary to focus on assessing students' comprehensive English application skills. 
H. Paying Attention to Cultivating Students' Creativity and Innovation

No matter in the past or in the increasingly internationalized world, creativity has become an eyecatching word. This also appears to be more and more important in adult English teaching. Students must improve self-learning ability by relying on their own level. This process has effectively cultivated students' innovative ability. By encouraging students to communicate and interact in the classroom, it is beneficial to develop their innovative ability and divergent thinking. Teachers are encouraged to use different teaching methods to cultivate students' practical ability and enrich adult English classes through the improvement of students' creative abilities and innovative spirits.

\section{CONCLUSION}

The application of multimedia technology in adult English teaching has greatly advanced the process of English teaching reform.

The processing and display of a variety of teaching information and materials has improved the students' sense of participation and learning efficiency, achieved the scientification teaching of adult English teaching, and provided students with rich resources, effective models and convenient conditions for their lifelong learning, which achieves personalized and individualized learning. With the increase of people's attention to multimedia English teaching and teachers' teaching practice, the network and multimedia technology will surely exert its potential teaching function and improve the English teaching level comprehensively.

\section{REFERENCES}

[1] Wang Qiuyuan. Application of multimedia technology in adult English teaching practice [J]. Chinese Adult Education, 2011, (20): 153-154. 王秋媛. 多媒体技术在成人英语教学实践中的应用 $[\mathrm{J}]$. 中国成人教育,2011,(20):153-154.

[2] Cai Jigang, Wu Shixing. Introducing multimedia network technology to reform the traditional teaching model [J]. Foreign Language World, 2003 ( 6) . 蔡基刚, 武世兴. 引进多媒体网络技术, 改革传统的教学 模式[J]. 外语界, 2003( 6) .

[3] Wei Zhouping. Main problems and countermeasures in adult college English teaching[J]. Chinese Adult Education, 2007,(7): 87- 88. 魏州 平. 成人大学英语教学中的主要问题和对策 [J]. 中国成人教 育, 2007,(7): 87-88.

[4] Huang Wei. The Application of Multimedia Teaching in Higher Vocational English Teaching [J]. Management Observer, 2009, (15): 137-138. 黄维. 多媒体教学在高职英语教学中的运用 [J]. 管理观 察,2009, (15) : 137-138. 